\title{
Migration characteristics of the Corail hydroxyapatite-coated femoral stem-a retrospective clinical evaluation and migration measurement with EBRA
}

\author{
Dietmar Dammerer ${ }^{1}$. Philipp Blum ${ }^{1}$ (D) David Putzer ${ }^{2} \cdot$ Dietmar Krappinger $^{1} \cdot$ Christof Pabinger $^{3}$. \\ Michael C. Liebensteiner ${ }^{1} \cdot$ Martin Thaler $^{1}$
}

Received: 18 September 2020 / Accepted: 29 April 2021 / Published online: 17 May 2021

(c) The Author(s) 2021

\begin{abstract}
Purpose Uncemented stem migration analysis by EBRA-FCA (Einzel-Bild-Roentgen Analyse, Femoral Component Analysis) has been seen to be a good predictive indicator for early implant failure. In this study, we investigated the migration behavior of a cementless press-fit stem after two years follow-up. Stem type and postoperative gap between collar and femur were evaluated as a risk factor.

Methods Applying a retrospective study design, we reviewed all consecutive patients who between 2013 and 2017 received a cementless press-fit Corail stem (DePuy Orthopaedics Inc., Warsaw, IN, USA) at our Department. We reviewed medical histories and performed radiological measurements using EBRA-FCA software.

Results A total of 109 stems in 105 patients (female: 60; male: 45) fulfilled our inclusion criteria. Mean age at surgery was 67.8 (range, 21.6-90.5) years. EBRA migration analysis showed a mean subsidence of $1.8 \mathrm{~mm}$ (range, 0.0-12.1) at final follow-up. At 18 months mean subsidence of collared stems was significantly lower than in the collarless group [1.3 mm (range, 0.0-7.6) vs. $3.2 \mathrm{~mm}$ (range, 0.5-10.7), $p=0.0104]$. Collared stems resting on the femoral cut presented a tendency to less subsidence than did collared stems showing a postoperative gap between collar and femur (1.3 vs. $2.0 \mathrm{~mm})$ without finding statistical significance $(p>0.05)$.

Conclusions Low subsidence and the migration pattern of the cementless press-fit stem may predict a good long-term result. Collared stems investigated in our study provide good stability and are able to prevent significant subsidence.

Trial registration number and date of registration: Number: 20181024-1875; Date: 2018-10-24
\end{abstract}

Keywords Stem subsidence · Total hip arthroplasty $\cdot$ Cementless $\cdot$ Einzel-Bild-Röntgen-Analyse (EBRA)

Philipp Blum

philippblum1@gmx.de

Dietmar Dammerer

dietmar.dammerer@tirol-kliniken.at

David Putzer

david.putzer@i-med.ac.at

Dietmar Krappinger

dietmar.krappinger@tirol-kliniken.at

Christof Pabinger

pabinger@opz.at

Michael C. Liebensteiner

michael.liebensteiner@i-med.ac.at
Martin Thaler

martin.thaler@i-med.ac.at

1 Department of Orthopaedics and Traumatology, Medical University of Innsbruck, Anichstrasse 35, 6020 Innsbruck, Austria

2 Department of Experimental Orthopaedics, Medical University of Innsbruck, Sonnenburgstr. 16, 6020 Innsbruck, Austria

3 Medical University of Innsbruck, Christoph-Probst-Platz 52, 6020 Innsbruck, Austria 


\section{Introduction}

Cemented as well as cementless femoral components in total hip arthroplasty (THA) yielded excellent long-term survival rates over $95 \%$ after ten years [1]. Nevertheless, the most common cause of failure in THA is aseptic loosening [2]. Previously published studies reported distal migration of the stem, called subsidence, which has shown to be a good predictive factor for early aseptic loosening [3-6]. According to Krismer et al. distal migration of the stem of more than $1.5 \mathrm{~mm}(\mathrm{~mm})$ detected with EBRA-FCA within the first two years is a well-established risk factor for early implant failure [7]. However, comparability is limited due to the inclusion of cemented and cementless stems by Krismer et al. [7]. Streit et al. rated a limit of $2.7 \mathrm{~mm}$ axial migration as critical for the cementless CLS stem (Zimmer Inc, Warsaw, IN, USA) within the first two years after surgery [6].

EBRA-FCA is a computer-assisted method for measuring the distal migration of femoral stems using standard anterior-posterior (ap) pelvic radiographs without requiring additional means at exposure (e.g. ball markers). It has proven accuracy and a sensitivity of more than $1 \mathrm{~mm}$ in detecting migration, as compared to RSA (roentgen stereophotogrammetric analysis) $[8,9]$.

The stem investigated in this study is the Corail ${ }^{\circledR}$ stem by DuPuy Synthes (DePuy Orthopaedics Inc., Warsaw, IN, USA). It is designed for the cementless press-fit application, offers various offset options and is available with or without collar [10]. According to the Australian Orthopaedic Association National Joint Replacement Registry, 5283 Corail stems were implanted in Australia in 2018, which makes it the most used cementless stem in primary THA [11].

In the present study, we investigated the clinical results and the migration behavior of the cementless Corail stem using EBRA-FCA with a follow-up of 24 months. Furthermore, we evaluated the possible influence of stem type and distance between collar and femur on stem subsidence.

\section{Material and methods}

The study was approved by the local ethics committee (Medical University of Innsbruck, Austria, Europe). We applied a retrospective study design and reviewed all consecutive patients who received a Corail stem at our Department between 2013 and 2017. During this time, a total of 217 Corail stems were implanted as part of a primary THA. The type of Corail stem was chosen by the surgeon depending on the patient's situation.

We investigated the medical histories for sociodemographic data, surgical approach, pre- and postoperative range of motion, body mass index, cut-to-suture time and the preoperative diagnosis for THA indication. Furthermore, the estimated blood loss was calculated using the formula of Mercuriali [12].

Axial stem migration and prosthetic stability of the stem were assessed retrospectively with EBRA-FCA (German: Einzel-Bild-Röntgen-Analyse, Femoral Component Analysis) from plain $\mathrm{x}$ rays $[7,8]$. A total of 19 reference points are defined on the femoral head $(n=7)$, the stem $(n=2)$, the femoral cortex $(n=8)$, and one each at the major and minor trochanter [8]. The EBRA-FCA software excludes radiographs with a comparability algorithm, which identifies significant positioning artifacts by comparing specific bone and prosthetic landmarks. Figure 1 shows the $\mathrm{x}$-rays of a collared and a collarless Corail stem including EBRAFCA references.

We followed patients with radiographs before discharge, six weeks after surgery, 12 months postoperatively and at the subsequent annual check-ups. Additional radiographs were performed if the patient voiced complaints after THA. All radiographs were taken with the same technique and following the EBRA protocol: anterior-posterior (AP) radiographs; patient standing in upright position and full weight-bearing. For EBRA-FCA analysis, a minimum of four radiographs per patient and a minimum of eight months radiological follow-up were required. Stem migration analysis was performed with EBRA-FCA by one independent investigator, who was not involved in the surgeries or postoperative treatment of the patients. The head sizes used for EBRA-FCA calibration were taken from the operation notes.

In addition, the influence that stem type (collared vs. collarless) and distance between collar and femur ( 0 vs. $>0 \mathrm{~mm}$ ) exerted on subsidence was investigated.

\section{Statistics}

Mean, median, range, and standard deviation were calculated for the various measurement parameters. For the analysis, Access and Excel (Microsoft Office Professional Plus 2010, Redmond, WA, USA) as well as Graph Pad Prism (Version 8.0, GraphPad Software, Inc., La Jolla, CA, USA) were used. Subsidence was classified as greater or less than 1.5 or $2.7 \mathrm{~mm}$ at 2-year follow-up [6,7]. All data were tested for normality using the Kolmogorov-Smirnov test. For comparison of the EBRA measurements at different time steps the Kruskal Wallis test was used. The EBRA measurements were compared by stem type using the Mann Whitney U-Test. When comparing the range of motion pre- and postoperatively the Mann Whitney U test was used. A p value of 0.05 was considered statistically significant. 

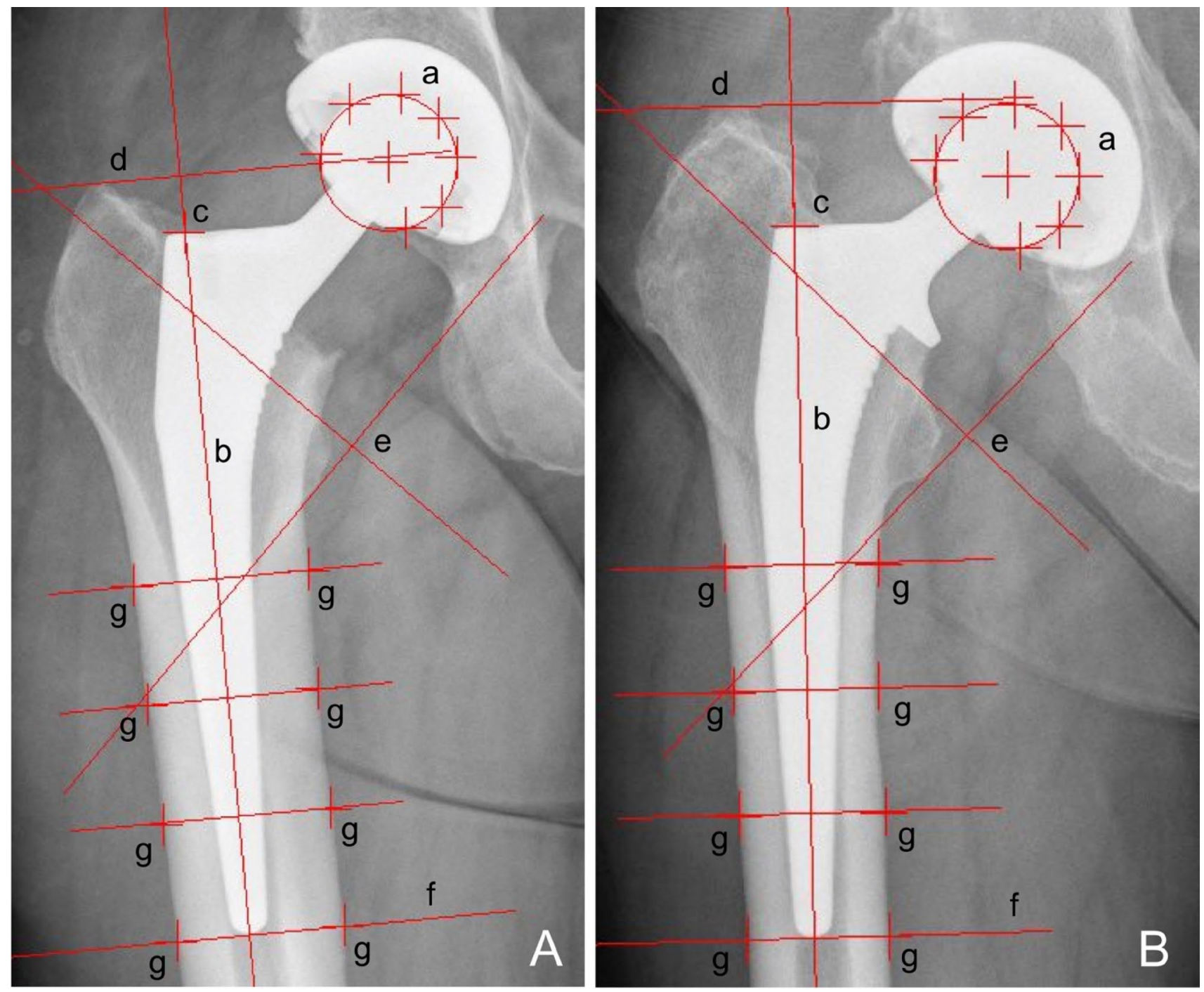

Fig. 1 Anterior to posterior $\mathrm{x}$ rays showing a collarless (A) and a collared (B) Corail stem with EBRA-FCA references a head points $\mathbf{b}$ stem axis $\mathbf{c}$ stem shoulder $\mathbf{d}$ major trochanter line $\mathbf{e}$ minor trochanter lines $\mathbf{f}$ tip-of-stem line $\mathbf{g}$ points at femoral bone contour

\section{Results}

A total of 109 stems in 105 patients (female: 60; male: 45) fulfilled our inclusion criteria. Of these 32 were collared standard stems, 40 collared high-offset stems, 7 collared coxa vara stems, 11 collarless standard stems and 13 collarless high-offset stems. For another six collared stems the offset version could not be assessed. In four patients a Corail stem was implanted bilaterally. Mean follow-up was 25.1 (range, 8-57) months. The preoperative diagnosis was osteoarthritis in 104 (95.4\%) hips, avascular necrosis of the femoral head in four (3.7\%) hips and hip dysplasia with secondary osteoarthritis in one (0.9\%) hip. The investigated stem was combined with a cementless press-fit Pinnacle cup (DePuy Orthopaedics Inc., Warsaw, IN, USA). The most used stem and head sizes were $12(22.9 \%)$ and $32 \mathrm{~mm}(89.9 \%)$, respectively. More details on patients' demographics and surgical procedure are shown in Tables 1 and 2.

EBRA-FCA analysis at 24 months follow-up was calculated for 67 of the 109 stems with an EBRA-FCA-given comparability limit of $3.0 \mathrm{~mm}$ (95\% confidence interval). A total of $469 \times$ rays were analyzed, $29(6.2 \%)$ radiographs rejected by the EBRA-FCA software. On average, 4.3 (range, 4-7) x rays per implant were analyzed. None of our patients had to be excluded from EBRA-FCA migration analysis. A complete set of radiographs at every single time step (e.g. six months, 12 months, etc.) was not available for each stem in our study. Therefore, total subsidence could not be calculated for all cases. This gives a different number of cases in the corresponding migration behavior analysis over time.

The EBRA-FCA analysis showed a mean migration of $0.9 \mathrm{~mm}$ (median 0.4; range 0.0-8.0) at six months, $1.2 \mathrm{~mm}$ 
Table 1 Patient demographics for the study group. Range is given in brackets

\begin{tabular}{lll}
\hline Number of patients & Female & 60 \\
& Male & 45 \\
& Total & 105 \\
Mean age (years) & & $67.8(21.6-90.5)$ \\
BMI (kg/m2) & & $26.8(17.4-50.8)$ \\
Cut-to-suture time (min) & & $80(36-200)$ \\
Surgical approach & Direct anterior approach & 107 \\
& Anterolateral approach & 2 \\
Surgical position & Supine & 109 \\
Preoperative diagnosis & Osteoarthritis & 104 \\
& Avascular necrosis of & 4 \\
& the femoral head & \\
Total blood loss (l) & Hip dysplasia & 1 \\
& & $1.2(0.1-5.0)$ \\
\hline
\end{tabular}

Table 2 Details of implanted components. Percentages are given in brackets

\begin{tabular}{llc}
\hline Stem product & Corail & $109[100.0]$ \\
Stem type & Collared & $85[78.0]$ \\
Stem offset & Collarless & $24[22.0]$ \\
& Standard & $43[39.5]$ \\
& High-offset & $53[48.6]$ \\
& Coxa vara & $7[6.4]$ \\
Cup product & n.a & $6[5.5]$ \\
\hline
\end{tabular}

n.a. not available (median 0.7; range 0.0-7.5) at 12 months, $1.7 \mathrm{~mm}$ (median 1.1 ; range $0.0-10.7$ ) at 18 months, $1.8 \mathrm{~mm}$ (median 1.3; range $0.0-12.1$ ) at 24 months after surgery. Thus, the main axial subsidence occurred particularly in the first 18 months postoperatively (Table 3 and Fig. 2). The calculated mean monthly axial implant migration was $0.15 \mathrm{~mm}$ within the first six months, $0.05 \mathrm{~mm}$ between six and 12 months, $0.09 \mathrm{~mm}$ between 12 and 18 months and less than $0.01 \mathrm{~mm}$ between 18 and 24 months after surgery. A statistically significant difference was found between six and 18 months $(\mathrm{p}=0.0065)$ and between six and 24 months $(P<0.0001)$. No statistically significant difference was found for any other subsidence measurements $(p>0.05)$.

Percentages of the migrated stems are given in Table 4.

In addition, the angle between stem and femur axis was $0.2^{\circ}$ (median $0.1^{\circ}$; range $0.0^{\circ}-1.1^{\circ}$ ) after six months, $0.4^{\circ}$ (median $0.4^{\circ}$; range $0.0^{\circ}-1.5^{\circ}$ ) after 12 months, $0.3^{\circ}$ (median $0.2^{\circ}$; range $0.0^{\circ}-1.2^{\circ}$ ) after 18 months and $0.4^{\circ}$ (median $0.3^{\circ}$; range $0.0^{\circ}-1.9^{\circ}$ ) after 24 months (Fig. 2). A statistically significant difference was found between six and 12 months $(p=0.0013)$ and between six and 24 months $(p<0.0001)$. No statistically significant difference could be found for any other angle measurements $(p>0.05)$.

Subgroup analysis of collared and collarless implants (Fig. 3) showed a mean subsidence of $0.7 \mathrm{~mm}$ (median 0.4 ; range $0.0-7.8$ ) vs. $1.4 \mathrm{~mm}$ (median 0.9 ; range $0.0-8.0$ ) after six months, $1.3 \mathrm{~mm}$ (median 0.8 ; range $0.0-7.5$ ) vs. $0.9 \mathrm{~mm}$ (median 0.3; range 0.0-4.3) after 12 months, $1.3 \mathrm{~mm}$ (median 0.9; range 0.0-7.6) vs. $3.2 \mathrm{~mm}$ (median 2.5 ; range $0.5-10.7$ ) after 18 months and $1.6 \mathrm{~mm}$ (median

Table 3 Mean total subsidence in millimeters $(\mathrm{mm})$ over time. Range is given in brackets

\begin{tabular}{llll}
\hline Subsidence of the Corail stem in mm (range) & 6 months $(\mathrm{n}=91)$ & 12 months $(\mathrm{n}=57)$ & 18 months $(\mathrm{n}=49)$ \\
\hline
\end{tabular}

Fig. 2 Mean and standard deviation (bars) of the measured subsidence and the angle between stem and anatomical femoral axis over the follow-up period of 24 months
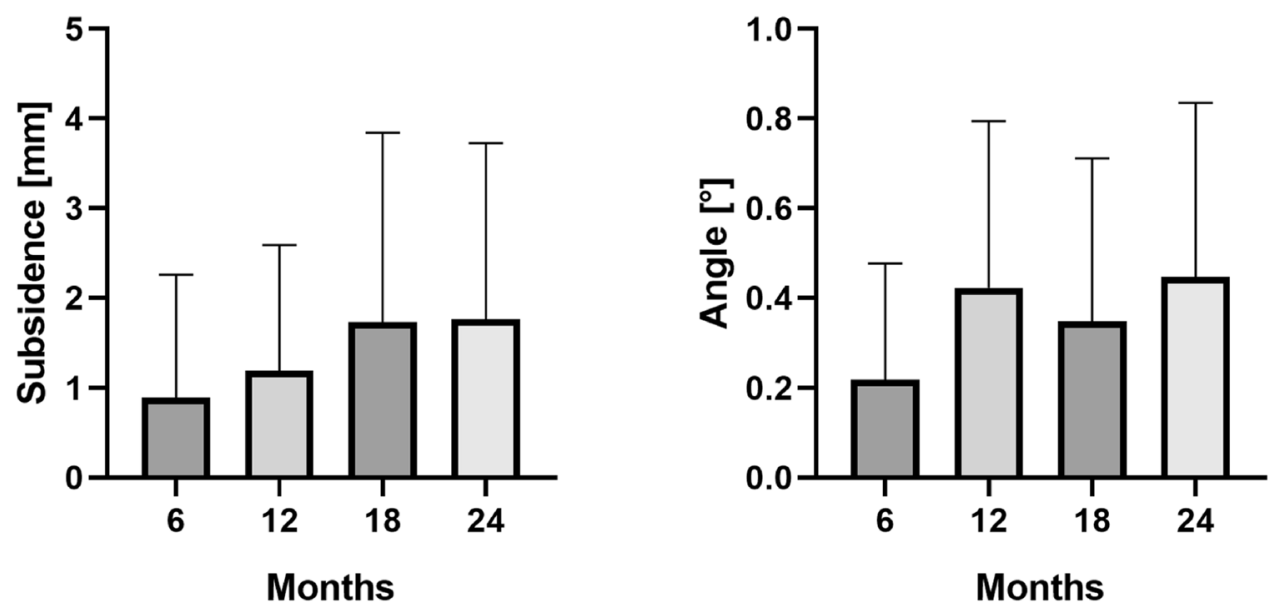
1.3; range $0.0-9.9$ ) vs. $2.2 \mathrm{~mm}$ (median 1.5 ; range $0.0-12.1$ ) after 24 months.

In addition, 40 of $85(47.1 \%)$ collared implants had immediate postoperative contact between the collar and the femoral cut. Collared implants presenting a postoperative gap between collar and femur revealed greater mean subsidence than did collar implants without gap after 24 months ( $2.0 \mathrm{~mm}$ vs. $1.3 \mathrm{~mm}$; median $1.3 \mathrm{~mm}$ vs. $1.1 \mathrm{~mm}$ ). However, no statistically significant differences could be found $(p>0.05)$. Further migration values at different time steps are shown in Fig. 4.
Pre- and postoperative comparison of the range of motion showed a mean improvement in flexion of $14^{\circ}$ (range, $-40^{\circ}-40^{\circ}, p<0.0001$ ), internal rotation $11^{\circ}$ (range, $-40^{\circ}-40^{\circ}, p<0.0001$ ), external rotation $7^{\circ}$ (range, $-15^{\circ}-45^{\circ}, p<0.0001$ ) and abduction $7^{\circ}$ (range, $-30^{\circ}-30^{\circ}$, $p<0.0001)$. No statistically significant improvement was found for hip adduction when comparing pre- and postoperative range of motion $(p=0.1391)$. While preoperatively a flexion $\geq 90^{\circ}$ was possible in only $74.3 \%$ of the hips, this increased to $94.5 \%$ postoperatively.
Table 4 Total subsidence in millimeters $(\mathrm{mm})$ over time. Percentages are given in square brackets

\begin{tabular}{lcccc}
\hline $\begin{array}{l}\text { Total subsid- } \\
\text { ence }(\mathrm{mm})\end{array}$ & 6 months $(n=91)$ & 12 months $(n=57)$ & 18 months $(n=49)$ & 24 months $(n=67)$ \\
\hline$\leq 1.5$ & $74[81.3]$ & $40[70.2]$ & $32[65.3]$ & $41[61.2]$ \\
$>1.5$ & $10[11.0]$ & $9[15.8]$ & $7[14.3]$ & $16[23.9]$ \\
$>2.7$ & $7[7.7]$ & $8[14.0]$ & $10[20.4]$ & $10[14.9]$ \\
\hline
\end{tabular}

Fig. 3 Boxplots of the measured subsidence are shown for collared and collarless implants. Whiskers and outliers (dots) were determined according to the Tuckey method

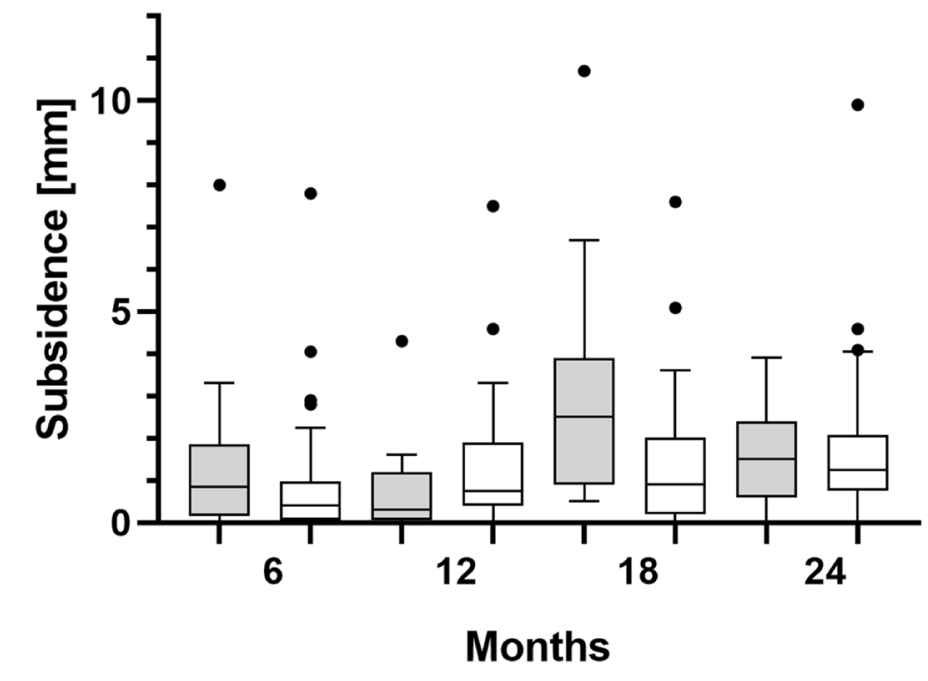

collarless

collared

Fig. 4 Boxplots of the measured subsidence are shown for collared implants with and without a gap between collar and osteotomy level. Whiskers and outliers (dots) were determined according to the Tuckey method

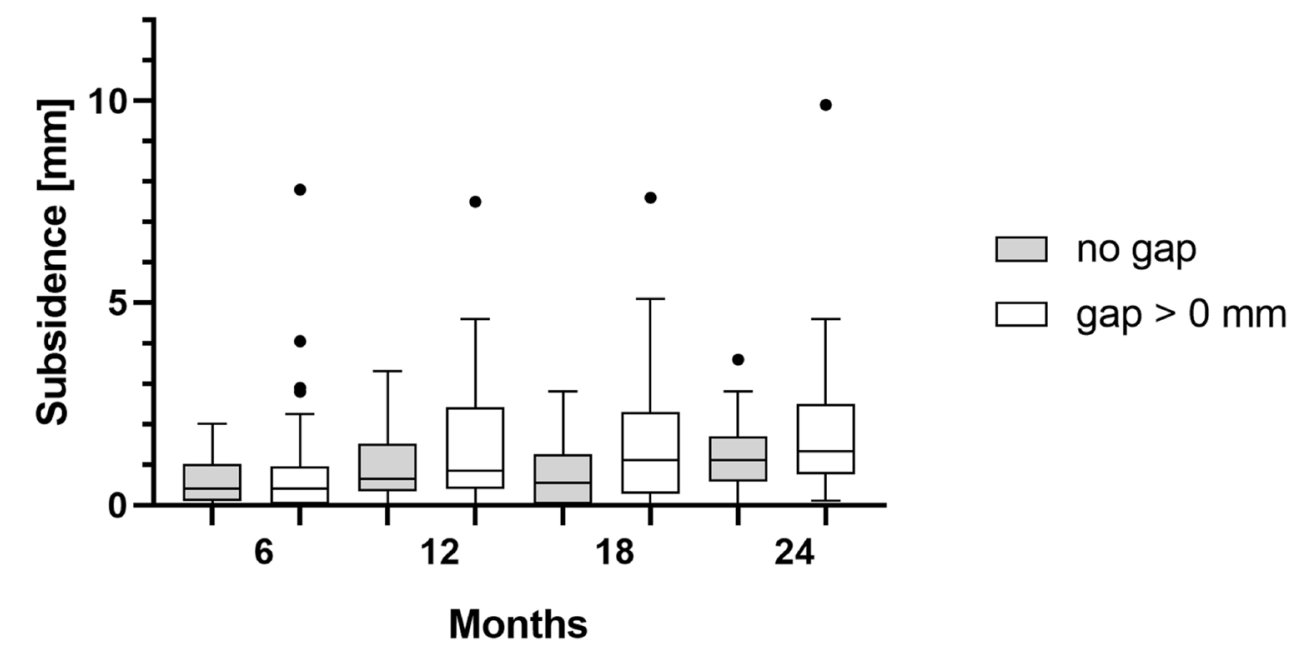




\section{Discussion}

As far as we know, this is the first study to characterize the migration behavior of the Corail stem using EBRA-FCA software. The most important finding of our study is a mean subsidence of $1.8 \mathrm{~mm}$ after a followup of 24 months. While the subsidence rate of collared stems was lower (collared $1.6 \mathrm{~mm}$ vs. collarless $2.2 \mathrm{~mm}$, $p>0.05)$ at 24 months, a statistically significant difference was only found between groups at 18 months $(p=0.0104)$. Furthermore, collared stems without a postoperative gap between collar and femur showed a tendency to less subsidence than collared stems with a gap did.

The use of cementless stems requires a high level of press fit to achieve primary implant stability [13]. Otherwise, subsidence can lead to aseptic loosening of the implant [7]. With a specificity of $100 \%$ and a sensitivity of $78 \%$ as compared with roentgen stereophotogrammetric analysis (RSA) for detection of migration of more than $1 \mathrm{~mm}$, EBRA-FCA is suitable for identifying and measuring the subsidence of femoral components in THA [8]. While RSA is considered to be the gold standard for migration measurement, EBRA offers the advantage of being a non-invasive method that can be used in our retrospective study design.

Several studies have already evaluated the subsidence of cementless stems using a variety of measurement techniques [14-19]. When investigating 30 collarless, standard offset Corail stems with RSA, Campbell et al. presented a mean migration of $0.58 \mathrm{~mm}$ after two years with the main subsidence occurring within the first six months [15]. In contrast, the mean subsidence measured by Ries et al. in 231 collared and collarless Corail stems amounted to $2.9 \mathrm{~mm}$ after a mean follow-up of seven months [18]. Subsidence was measured as the distance between stem shoulder and major trochanter [18]. EBRA-FCA analysis by Stihsen et al. showed a mean subsidence of $1.38 \mathrm{~mm}$ for 105 cementless Vision 2000 stems (DePuy, Warsaw, IN, USA) [20]. Compared to these results, we can present a mean subsidence of $1.8 \mathrm{~mm}$ after two years. In our study, the main subsidence occurred in the first six months, showing an axial migration of $0.15 \mathrm{~mm} / \mathrm{month}$, and we can thus confirm the observation made by Campbell et al. [15]. Selvaratnam et al. and Al-Najim et al., who monitored the Corail stem at shorter intervals, reported that the main subsidence occurred in the first six weeks after surgery [21, 22]. Selvaratnam et al. hypothesized that early migration of cementless Corail stems is a form of impaction rather than a real subsidence leading to implant instability [21]. The phenomenon of early subsidence with later stabilization is not unknown and was already described in 1999 by Krismer et al. [7]. It is assumed that secondary stabilization can lead to long-lasting survival of the implant [7].

The Corail stem is available with or without a collar. As mentioned by the company, collared stems are available to prevent subsidence and provide additional rotational stability in patients with osteopenic bone [10]. In 1997, Meding et al. investigated collared and collarless femoral stems in uncemented primary THA without finding significant differences in adequacy of fixation or clinical scores [14]. However, Demey et al. performed a comparative bilateral cadaver study showing significantly greater immediate stability of collared stems, in that they withstood greater vertical and horizontal forces before subsidence occurred [17]. Thanks to this benefit, Demey et al. routinely use collared stems in uncemented primary THA [17]. Ries et al. confirmed the findings of Demey et al. by showing a significantly greater subsidence of collarless than of collared Corail stems (3.1 mm vs. $1.6 \mathrm{~mm}$ ) after a mean follow-up of seven months [18]. In our study, the group of collarless Corail stems also showed greater mean subsidence than did the collared stems after two years of follow-up ( $2.2 \mathrm{vs.} 1.6 \mathrm{~mm}$, respectively), whereby statistical significance was found only for measurements at 18 months.

In addition to the used stem type, biomechanical tests show that the immediate postoperative distance between collar and femur seems to influence the primary stability of the implant [17]. Al-Najim et al. suggested that further stem subsidence is prevented once the collar is in contact with the medial femoral cut [22]. While in the Meding et al. study group 39\% of the stem collars rested on the femur [14], this figure was $47.1 \%$ in our study. We found a lower mean subsidence of collared stems with immediate postoperative contact to the femoral cut than of stems without after two years follow-up (1.3 vs. $2.0 \mathrm{~mm}$ ). Although no statistically significant differences were found, the detected tendency at all measurement steps leads us to hypothesize that a collar resting on the femoral cut might prevent increased subsidence.

This study has several limitations, including the retrospective methodology. As a result, some of the treated patients had to be excluded from the cohort, possibly making the study more prone to selection bias. Furthermore, there were a varying number of radiographs and duration of follow-up for each hip. This may have influenced the migration results due to the smoothing function within the software and made it difficult to follow the exact outcome of each individual implant. The unequal distribution of collared and collarless cases has to be mentioned as a possible bias, which may have influenced the final result. In addition, we did not compare our results with another patient cohort using a different stem design. However, migration analysis results are well published, and therefore our results can be compared with previously published results, which, however, did not compare their results with those of another 
patient cohort. Furthermore, some patient characteristics (e.g. smoking, osteoporosis), which might have influenced the clinical outcome of the implant, could not be assessed.

In conclusion, EBRA-FCA analysis of the Corail stem showed low mean subsidence, reduction of migration speed and low tilting of the stem with good clinical function at 24 months. At 18 months mean subsidence of collared stems was significantly lower than for the collarless group. Collared stems resting on femoral cut presented a tendency to less subsidence than did collared stems showing a postoperative gap between collar and femur. Further investigations of a larger cohort are necessary to identify possible clinical differences in outcome between the two groups over the long term.

Acknowledgements This research did not receive any specific grant from funding agencies in the public, commercial, or not-for-profit sectors.

Authors' contributions All listed authors have substantially contributed to this study. All authors have reviewed and confirmed the accuracy of the whole manuscript.

Funding Open access funding provided by University of Innsbruck and Medical University of Innsbruck. This research did not receive any specific grant from funding agencies in the public, commercial, or not-for-profit sectors.

Data availability Data will be sent if necessary.

\section{Declarations}

Conflict of interests The authors declare that they have no conflicts of interests.

Ethical approval The local ethics committee approved the study.

Informed consent Not applicable. Retrospective study design.

Consent for publication All authors have reviewed and confirmed the accuracy of the whole manuscript.

Open Access This article is licensed under a Creative Commons Attribution 4.0 International License, which permits use, sharing, adaptation, distribution and reproduction in any medium or format, as long as you give appropriate credit to the original author(s) and the source, provide a link to the Creative Commons licence, and indicate if changes were made. The images or other third party material in this article are included in the article's Creative Commons licence, unless indicated otherwise in a credit line to the material. If material is not included in the article's Creative Commons licence and your intended use is not permitted by statutory regulation or exceeds the permitted use, you will need to obtain permission directly from the copyright holder. To view a copy of this licence, visit http://creativecommons.org/licenses/by/4.0/.

\section{References}

1. Kärrholm J, Mohaddes M, Odin D, Vinblad J, Rogmark C, Rolfson O (2018) Swedish Hip Arthroplasty Register Annual Report 2017. https://registercentrum.blob.core.windows.net/shpr/r/Eng Arsrapport_2017_Hoftprotes_final-Syx2fJPhMN.pdf

2. Johnsen SP, Sørensen HT, Lucht U, Søballe K, Overgaard S, Pedersen AB (2006) Patient-related predictors of implant failure after primary total hip replacement in the initial, short- and long-terms. A nationwide Danish follow-up study including 36,984 patients. J Bone Joint Surg Br 88:1303-1308. https://doi.org/10.1302/0301620X.88B10.17399

3. Freeman MA, Plante-Bordeneuve P (1994) Early migration and late aseptic failure of proximal femoral prostheses. J Bone Joint Surg Br 76:432-438

4. Walker PS, Mai SF, Cobb AG, Bentley G, Hua J (1995) Prediction of clinical outcome of THR from migration measurements on standard radiographs. A study of cemented Charnley and Stanmore femoral stems. J Bone Joint Surg Br 77:705-714

5. Kroell A, Beaulé P, Krismer M, Behensky H, Stoeckl B, Biedermann R (2009) Aseptic stem loosening in primary THA: migration analysis of cemented and cementless fixation. Int Orthop 33:1501-1505. https://doi.org/10.1007/s00264-008-0701-1

6. Streit MR, Haeussler D, Bruckner T, Proctor T, Innmann MM, Merle C, Gotterbarm T, Weiss S (2016) Early migration predicts aseptic loosening of cementless femoral stems: a long-term study. Clin Orthop Relat Res 474:1697-1706. https://doi.org/10.1007/ s11999-016-4857-5

7. Krismer M, Biedermann R, Stöckl B, Fischer M, Bauer R, Haid C (1999) The prediction of failure of the stem in THR by measurement of early migration using EBRA-FCA. Einzel-Bild-Roentgen-Analyse-femoral component analysis. J Bone Joint Surg Br 81:273-280. https://doi.org/10.1302/0301-620x.81b2.8840

8. Biedermann R, Krismer M, Stöckl B, Mayrhofer P, Ornstein E, Franzén H (1999) Accuracy of EBRA-FCA in the measurement of migration of femoral components of total hip replacement. EinzelBild-Röntgen-Analyse-femoral component analysis. J Bone Joint Surg Br 81:266-272. https://doi.org/10.1302/0301-620x.81b2. 8842

9. Abrahams JM, Callary SA, Jang SW, Hewitt J, Howie DW, Solomon LB (2020) Accuracy of EBRA-cup measurements after reconstruction of severe acetabular defects at revision THR. J Orthop Res. https://doi.org/10.1002/jor.24623

10. DePuy Synthes (2019) Corail hip system. https://www.corailpinn acle.net/sites/default/files/2019-09/117227-190624-corail-prima ry-surgical-technique.pdf. Accessed 15 Sept 2020.

11. Registry AOANJR (2019) Annual report 2019. https://aoanjrr. sahmri.com/documents/10180/668596/Hip\%2C+Knee+\%26+ Shoulder+Arthroplasty/c287d2a3-22df-a3bb-37a2-91e6c00bfc f0. Accessed 15 Sept 2020.

12. Gibon E, Courpied JP, Hamadouche M (2013) Total joint replacement and blood loss: what is the best equation? Int Orthop 37:735-739. https://doi.org/10.1007/s00264-013-1801-0

13. Søballe K, Hansen ES, B-Rasmussen H, Jørgensen PH, Bünger C (1992) Tissue ingrowth into titanium and hydroxyapatite-coated implants during stable and unstable mechanical conditions. J Orthop Res 10:285-299. https://doi.org/10.1002/jor.1100100216

14. Meding JB, Ritter MA, Keating EM, Faris PM (1997) Comparison of collared and collarless femoral components in primary uncemented total hip arthroplasty. J Arthroplasty 12:273-280. https:// doi.org/10.1016/s0883-5403(97)90023-1

15. Campbell D, Mercer G, Nilsson KG, Wells V, Field JR, Callary SA (2011) Early migration characteristics of a hydroxyapatitecoated femoral stem: an RSA study. Int Orthop 35:483-488. https://doi.org/10.1007/s00264-009-0913-z 
16. Faisal M, Thomas G, Young SK (2011) Subsidence of the Corail femoral component in the elderly A retrospective radiological review. Hip Int 21:325-329. https://doi.org/10.5301/HIP.2011. 8409

17. Demey G, Fary C, Lustig S, Neyret P, si Selmi T, (2011) Does a collar improve the immediate stability of uncemented femoral hip stems in total hip arthroplasty? A bilateral comparative cadaver study. J Arthroplasty 26:1549-1555. https://doi.org/10.1016/j. arth.2011.03.030

18. Ries C, Boese CK, Dietrich F, Miehlke W, Heisel C (2019) Femoral stem subsidence in cementless total hip arthroplasty: a retrospective single-centre study. Int Orthop 43:307-314. https://doi. org/10.1007/s00264-018-4020-x

19. Critchley O, Callary S, Mercer G, Campbell D, Wilson C (2020) Long-term migration characteristics of the Corail hydroxyapatitecoated femoral stem: a 14-year radiostereometric analysis followup study. Arch Orthop Trauma Surg 140:121-127. https://doi.org/ 10.1007/s00402-019-03291-8
20. Stihsen C, Radl R, Keshmiri A, Rehak P, Windhager R (2012) Subsidence of a cementless femoral component influenced by body weight and body mass index. Int Orthop 36:941-947. https:// doi.org/10.1007/s00264-011-1360-1

21. Selvaratnam V, Shetty V, Sahni V (2015) Subsidence in collarless corail hip replacement. Open Orthop J 9:194-197. https://doi.org/ 10.2174/1874325001509010194

22. Al-Najjim M, Khattak U, Sim J, Chambers I (2016) Differences in subsidence rate between alternative designs of a commonly used uncemented femoral stem. J Orthop 13:322-326. https://doi.org/ 10.1016/j.jor.2016.06.026

Publisher's Note Springer Nature remains neutral with regard to jurisdictional claims in published maps and institutional affiliations. 